\title{
Impact of Different Aortic Entry Tear Sites on Early Outcomes and Long-Term Survival in Patients with Stanford A Acute Aortic Dissection
}

\author{
Julia Merkle ${ }^{1}$ Anton Sabashnikov ${ }^{1}$ Antje Christin Deppe ${ }^{1} \quad$ Saskia Weber $^{1}$ Navid Mader $^{1}$ \\ Yeong-Hoon Choi ${ }^{1}$ Oliver Liakopoulos ${ }^{1}$ Ferdinand Kuhn-Régnier ${ }^{1}$ Thorsten Wahlers ${ }^{1}$
}

${ }^{1}$ Department of Cardiothoracic Surgery, University Hospital of
Cologne, Cologne, Germany

Thorac Cardiovasc Surg 2019;67:363-371.
Address for correspondence Julia Merkle, MD, Department of Cardiothoracic Surgery, University Hospital of Cologne, Kerpener Str. 62, 50924 Cologne, Germany (e-mail: Julia.merkle@uk-koeln.de).

\begin{abstract}
\section{Keywords}

- Stanford A acute aortic dissection

- ascending aorta

- aortic hemiarch

- aortic arch

- outcomes

- entry tear

Background Stanford A acute aortic dissection (AAD) is a life-threatening emergency. The aim of this study was to compare the impact of three different aortic entry tear sites on early outcomes and long-term survival of patients with Stanford A AAD.

Methods From January 2006 to April 2015, a total of 240 consecutive patients with diagnosed Stanford A AAD underwent emergent, isolated surgical aortic repair in our center. Patients were divided into three groups comprising isolated ascending aorta, proximal aortic arch, and distal aortic arch entry tear site and were followed up for up to 9 years.

Results Thirty-day mortality as well as major cerebrovascular events were significantly different between the three groups ( $p=0.007$ and $p=0.048$, respectively). Overall cumulative short- and long-term survival of all patients revealed significant differences (Log-Rank $p=0.002$ ), whereas survival of all patients free from major cerebrovascular events was similar (Log-Rank $p=0.780$ ). Subgroup analysis of short- and long-term survival of patients showed significant differences in terms of men (Log-Rank $p=0.043$ ), women (Log-Rank $p=0.004$ ), patients over 65 years of age (Log-Rank $p=0.007$ ), and hypertensive patients (Log-Rank $p=0.003$ ). Kaplan-Meier survival estimation plots significantly showed poorest survival for distal aortic arch entry tear site group.

Conclusion The location of the primary entry tear in patients with Stanford A AAD significantly influences early outcomes, short- and long-term survival of patients, whereas survival of patients free from major cerebrovascular events showed similar results among the three groups. Distal aortic entry tear site showed poorest outcomes and survival.
\end{abstract}

\section{Introduction}

Stanford A acute aortic dissection (AAD) is a life-threatening cardiac emergency. ${ }^{1}$ Every physician treating patients with Stanford A AAD knows the clinical scenario of an initially stable patient suddenly turning into an urgent emergency. It is associated with a high mortality rate up to $50 \%$ in the first 48 hours after symptom onset, if untreated. ${ }^{2}$ Thus, Stanford A

received

February 8, 2018

accepted after revision

March 26, 2018

published online

June 13, 2018

AAD being involved with one of the three aortic entry tear sites should be immediately repaired to avoid fatal extension of the tear into pericardium, pleural space, coronary arteries, or aortic root. ${ }^{3}$ If the aortic entry tear was located after the aortic valve and before branch-off of the brachiocephalic trunk, ascending aortic repair was performed in our institution. If the aortic entry tear was located in the curvature, aortic hemiarch replacement was performed. If the aortic

(c) 2019 Georg Thieme Verlag KG Stuttgart · New York
DOI https://doi.org/ 10.1055/s-0038-1649511. ISSN 0171-6425. 
entry tear was involved in the whole aortic arch including supra-aortic vessels, whole aortic arch was replaced with reinsertion of the vessels.

Generally, the goal of surgical treatment of Stanford A AAD should be exclusion of the primary entry tear. ${ }^{4}$ Therefore, it seems reasonable and necessary to locate preoperatively the exact entry tear site using diagnostic tools, such as computed tomography (CT). ${ }^{4}$ In literature, different classifications of entry tear locations of Stanford A AAD were described. Some authors categorize entry tear sites as to be in the greater or lesser curvature, others as being located in proximal, middle, or distal ascending aorta. ${ }^{5,6}$ Despite these different classifications, most studies agree with the fact that the more distal the location of an entry tear is, the more challenging the surgical procedure might be with higher mortality and poorer long-term survival. ${ }^{5}$ Some studies reported that entry tear site in the aortic arch appeared up to $12.5 \%$ of all Stanford A dissections. ${ }^{5}$ However, there is little evidence available analyzing the impact of different aortic entry tear sites on patients with Stanford A AAD on early outcomes and especially on short- and long-term survival. Some patient-related preoperative baseline characteristics have already been well analyzed, such as impact of hypertension or age on the development of Stanford A AAD. ${ }^{7}$ Nevertheless, the impact of different entry tear sites on early outcomes, short- and long-term survival has not yet been well analyzed. In literature, there is poor information concerning this rigorous issue. Differentiated analysis of the impact of three different aortic entry tear sites would help to improve surgical strategy and perioperative setting.

The purpose of this study was to evaluate and compare the impact of three different aortic entry tear sites in patients with Stanford A AAD on early outcomes, short- and longterm survival.

\section{Methods}

\section{Study Design}

The study design is a retrospective analysis of prospectively collected registry data.

\section{Patients and Variables}

An analysis of all consecutive patients diagnosed with Stanford A AAD referred to our institution for emergent surgical treatment from January 2006 to April 2015 was performed with focus on the impact of three different aortic entry tear sites on early outcomes, short- and long-term survival. After exclusion of patients who deceased prior to surgery, a total of 240 subjects remained in the present analysis. Patients were divided into three groups according to the location of primary aortic entry tear. Incidence of entry tear site in isolated ascending aorta occurred in 164 cases, in proximal aortic arch in 45 cases, and in distal aortic arch in 31 cases. Primary end points were short- and long-term survival of patients and survival of patients free from major cerebrovascular events with up to 9-year follow-up. Secondary end points were early postoperative adverse events. Preoperative baseline demographics and characteristics as well as outcomes for the three different aortic entry tear site groups were compared using univariate analysis. Subsequently, multinominal logistic regression was performed for subgroup analysis comparing isolated ascending aortic entry tear site group with proximal or/and distal aortic arch entry tear site group. To address the impact of the different aortic entry tear sites on short- and long-term survival of patients as well as survival of patients free from major cerebrovascular events and subgroup analysis for survival of men, women, patients under and above 65 years of age and hypertensive patients were analyzed.

Follow-up was obtained through direct contact with patients and patients' relatives, general practitioners and local hospitals, as well as through data collection from our institutional quality information management system and electronic documentation system. In cases when patients or patients' next of kin could not be contacted, the cutoff of the study for those particular patients was set as the date of the last documented follow-up contact. No patients were lost from follow-up. Patients were contacted between 6 months and 1 year after surgery. They were asked for repair or any conspicuous features and were admitted for a control CT scan to evaluate need for secondary surgical intervention.

\section{Surgical Procedure}

Sabashnikov et al described surgical procedure for Stanford A AAD. ${ }^{8,9}$ Depending on the identification of the location of the aortic entry tear in the CT scan before surgery extent of surgery was planned. Moreover, if the exact location of the primary aortic entry tear was unclear, extent of aortic repair and the very entry tear site were in detail reevaluated during surgery due to proper intraoperative visual inspection to exclude a possible communication between lumina.

Access to the surgical field was ensured through median sternotomy, whereas cannulation was performed either prior to sternotomy through the right axillary artery with a single purse string suture with 5-0 Prolene and an arterial cannula (Fem-Flex II; Edwards Lifescience, Irvine, California, United States), through femoral artery after surgical cut down using 5-0 Prolene and an arterial cannula (Fem-Flex II; Edwards Lifescience, Irvine, California, United States) or directly through the aortic arch after opening the chest with a double purse string suture with 4-0 Prolene for direct aortic cannulation. A bolus of unfractionated heparin of 300 to $400 \mathrm{IU}$ per $\mathrm{kg}$ body weight was administered prior to cannulation and establishment of cardiopulmonary bypass (CPB) to achieve activated clotting time $>400$ second. Venous cannulation was performed through the right atrium using a double-stage cannula (Maquet Cardiopulmonary AG, Rastatt, Germany). After initiation of systemic cooling on $\mathrm{CPB}$, a left ventricle vent catheter was usually placed through the right superior pulmonary vein. The aortic cross clamp was applied to the proximal aspect of the aortic arch alternatively the ascending aorta was incised and opened in circulatory arrest. Standard cannulation strategy to go onpump was via the axillar artery unless there was a tear or damage to the inner wall of the axillar artery. However, some experienced surgeons were proponents of direct cannulation independent of the involvement of the axillary artery. The 
final decision regarding cannulation strategy in each case was made by experienced attending surgeons who performed the procedures. In cases of axillary cannulation, aortic cannula was placed and secured in the right axillar artery prior to sternotomy. In cases of direct aortic or femoral cannulation, a short period of hypothermic circulatory arrest (HCA) was initiated for inspection of the aortic arch followed by an extended period of selective cerebral perfusion (SCP) and moderate hypothermia for distal anastomosis. In cases of axillary cannulation, a short period of HCA was avoided as cerebral perfusion was ensured through the right carotid artery after clamping the brachiocephalic trunk. In cases of central cannulation after completing the distal anastomosis, the arterial cannula was inserted into the prosthesis, the prosthesis was clamped, CPB was restarted, and the patient was rewarmed. While rewarming, the anastomosis between the proximal and the distal prosthesis was performed, and the aortic clamp was removed after careful de-airing procedure. A meticulous hemostasis was performed before closing the chest, whereas transfusion requirements were guided using thromboelastography available in our unit. ${ }^{8,9}$

\section{Statistical Analysis}

IBM SPSS Statistics for Windows, Version 25 (IBM Corp. Released 2017. Armonk, New York, United States, IBM Corp) was used for statistical analysis. All data were presented as continuous or categorical variables. Continuous data were checked for normality using one sample Kolmogorov-Smirnov test and histograms. All continuous variables were expressed as means \pm standard deviation for normally distributed variables or medians (interquartile ranges) for non-normally distributed continuous variables. Categorical data were expressed as total numbers and percentages. Statistical comparisons of continuous variables were performed using unpaired analysis of variance for normally distributed and nonparametric Kruskal-Wallis test for non-normally distributed variables, whereas categorical variables were assessed using Pearson's $X^{2}$ test or Fisher's exact test depending on the minimal expected count in each crosstab. Multinominal logistic regression analysis was performed for subgroup analysis comparing odds ratios (OR) of ascending aortic entry tear group versus proximal aortic arch entry tear group or distal aortic arch entry tear group. Kaplan-Meier survival estimation model was performed for short- and long-term survival up to 9-year follow-up comparing the impact of three different aortic entry tear site groups, whereas Breslow (Generalized Wilcoxon) test was applied for the calculation of significances for earlier (shortterm) and Log-Rank (Mantel-Cox) test for later (long-term) follow-up phases.

\section{Results}

\section{Univariate Analysis}

Univariate analysis comparing all three groups in terms of demographics, preoperative baseline, and clinical characteristics showed some statistically significant differences (-Table 1). Left ventricular ejection fraction $(p=0.037)$, incidence of aortic valve pathology ( $p=0.003$ ), and preoperative fibrinogen level $(p=0.029)$ significantly differed among the three groups. All other preoperative baseline characteristics showed similar results $(p>0.005)$. Interestingly, most aortic valve pathologies appeared to be significantly associated with an entry tear located in the isolated ascending aorta (48.7\%) versus incidence of entry tear in proximal (25.1\%) or distal aortic arch (26.2\%). Further, there were statistically significant differences of surgical strategy in terms of isolated ascending aortic repair group $(p<0.001)$, aortic hemiarch repair group $(p=0.002)$, and aortic arch repair group $(p<0.001)$. Additionally, use of selective brain perfusion showed statistically significant differences among the three entry tear site groups $(p<0.001)$ as well as cannulation in axillary arteria or ascending aorta ( $p=0.012$ and $p=0.036$, respectively). Further, selection of cardioplegia according to Buckberg, Calafiore, or Bretschneider was similarly distributed.

Intraoperative and early postoperative outcomes showed significant differences in distal aortic arch entry tear group in comparison to isolated ascending aortic and proximal aortic arch entry tear group in terms of higher cross clamp time: isolated ascending aortic entry group $(78(61 ; 115)$ versus proximal aortic arch entry group $99(77 ; 124)$ versus distal aortic arch entry group $134(101 ; 172) \min , p<0.001)$, longer duration of surgery $(313(245 ; 410)$ versus 322 $(257 ; 398)$ versus $402(286 ; 490) \mathrm{min}, p=0.030)$, longer CPB time $(165(121 ; 211)$ versus 193(155;215) versus 262 (171;262), $\quad p<0.001)$, longer selective brain perfusion time $(20(12 ; 33)$ versus $42(25 ; 62)$ versus $55(38 ; 78) \mathrm{min}$, $p<0.001)$, longer reperfusion time $(64(44 ; 83)$ versus 71 $(60 ; 85)$ versus $91(54 ; 145)$ min, $p=0.024)$, longer mechanical ventilation $(2(1 ; 6)$ versus $4(2 ; 10)$ versus $4(1 ; 17)$ days, $p=0.009$ ), higher drainage output over 24 hours (959 $(578 ; 1970)$ versus $1485(985 ; 1982)$ versus $2210(700 ; 3000)$ $\mathrm{mL}, p=0.009)$ and longer intensive care unit stay $(5(2 ; 12)$ versus $9(4 ; 13)$ versus $14(3 ; 24)$ days, $p=0.012)$.

Moreover, significantly higher incidence of major cerebrovascular events (ischemic or hemorrhagic stroke) occurred in proximal aortic arch entry tear group in $27.3 \%$, in isolated ascending aorta in $12.4 \%$, and in distal aortic entry tear group in $20.7 \%$ of all cases $(p=0.048)$. Further, incidence of gastrointestinal complications, 30-day mortality, and reopening for bleeding showed significantly highest incidence in proximal aortic arch entry tear group (24.1\% $p=0.040$ versus $38.7 \% p=0.007$ versus $37.9 \% p=0.047$, respectively). All other perioperative early outcomes were similarly distributed $(p>0.05)$ ( - Tables 2 and 3 ).

\section{Multinominal Logistic Regression Analysis}

Multinominal logistic regression analysis was applied for subgroup analysis in terms of three different aortic entry tear site groups with focus on incidence of major cerebrovascular events, gastrointestinal complications, bleeding, need for reopening, in-hospital, and 30-day mortality. In terms of major cerebrovascular events, comparison of proximal aortic arch entry tear group with isolated ascending aortic entry tear group showed a nearly threefold higher incidence $(\mathrm{OR}=2.65$, 
Table 1 Association of demographics and preoperative baseline characteristics for groups with aortic entry tear site in isolated ascending aorta, proximal aortic arch, and distal aortic arch

\begin{tabular}{|c|c|c|c|c|}
\hline & $\begin{array}{l}\text { Entry ascending } \\
\text { aorta }\end{array}$ & $\begin{array}{l}\text { Entry proximal } \\
\text { aortic arch }\end{array}$ & $\begin{array}{l}\text { Entry distal } \\
\text { aortic arch }\end{array}$ & $p$ Value \\
\hline Age (years) & $63(49 ; 72)$ & $69(55 ; 76)$ & $63(55 ; 72)$ & 0.093 \\
\hline Height $(\mathrm{cm})$ & $174(165 ; 180)$ & $175(166 ; 181)$ & $178(172 ; 180)$ & 0.115 \\
\hline Weight $(\mathrm{kg})$ & $80(68 ; 90)$ & $83(71 ; 93)$ & $82(75 ; 93)$ & 0.312 \\
\hline Gender (male) & $103(62.8 \%)$ & $26(57.8 \%)$ & $24(77.4 \%)$ & 0.195 \\
\hline Gender (female) & $61(37.2 \%)$ & $19(42.2 \%)$ & $7(22.6 \%)$ & 0.195 \\
\hline $\operatorname{LVEF}(\%)$ & $60(52 ; 60)$ & $60(55 ; 60)$ & $55(41 ; 60)$ & 0.037 \\
\hline Euroscore & $11(9 ; 14)$ & $12(9 ; 15)$ & $12(9 ; 14)$ & 0.290 \\
\hline Logistic Euroscore & $28(15 ; 42)$ & $34(16 ; 51)$ & $31(17 ; 49)$ & 0.246 \\
\hline Reduced perfusion & $50(30.5 \%)$ & $9(20.0 \%)$ & $11(35.5 \%)$ & 0.277 \\
\hline Pericardial effusion & 73 (44.5\%) & $20(44.4 \%)$ & $15(48.4 \%)$ & 0.921 \\
\hline Coronary dissection & $20(12.2 \%)$ & $4(8.9 \%)$ & $1(3.2 \%)$ & 0.303 \\
\hline Neurology normal & $116(70.7 \%)$ & $33(73.3 \%)$ & $19(63.3 \%)$ & 0.634 \\
\hline Neurology weak & $15(9.1 \%)$ & $7(15.6 \%)$ & $4(13.3 \%)$ & 0.425 \\
\hline Neurology coma & $33(20.1 \%)$ & $5(11.1 \%)$ & $7(23.3 \%)$ & 0.312 \\
\hline \multicolumn{5}{|l|}{ Comorbidities } \\
\hline Arterial hypertension & 117 (71.3\%) & $39(86.7 \%)$ & $25(80.6 \%)$ & 0.082 \\
\hline Diabetes mellitus & $13(7.9 \%)$ & $1(2.2 \%)$ & $4(12.9 \%)$ & 0.207 \\
\hline Elevated creatinine $^{\mathrm{a}}$ & $52(31.7 \%)$ & $11(24.4 \%)$ & $12(38.7 \%)$ & 0.409 \\
\hline Peripheral vascular disease & $11(6.7 \%)$ & $2(4.4 \%)$ & $2(6.5 \%)$ & 0.856 \\
\hline Coronary artery disease & $29(17.7 \%)$ & $9(20.0 \%)$ & $7(22.6 \%)$ & 0.792 \\
\hline Aortic valve pathology & $79(48.2 \%)$ & $11(24.4 \%)$ & $8(25.8 \%)$ & 0.003 \\
\hline Connective tissue disorder $^{\mathrm{b}}$ & $3(3.2 \%)$ & $1(2.8 \%)$ & $0(0.0 \%)$ & 0.614 \\
\hline \multicolumn{5}{|l|}{ Blood and coagulation parameters } \\
\hline Hemoglobin $(\mathrm{g} / \mathrm{dL})$ & $13(12 ; 14)$ & $13(11 ; 14)$ & $13(11 ; 14)$ & 0.281 \\
\hline Platelets preoperatively $(\mathrm{U})$ & $178(140 ; 236)$ & $190(157 ; 226)$ & $183(148 ; 304)$ & 0.585 \\
\hline Fibrinogen preoperatively $(\mathrm{g} / \mathrm{L})$ & $3.1(2.5 ; 3.5)$ & $2.6(2.1 ; 3.0)$ & $4.3(2.7 ; 5.4)$ & 0.029 \\
\hline aPTT preoperatively & $29(26 ; 35)$ & $29(26 ; 35)$ & $31(27 ; 34)$ & 0.705 \\
\hline Quick & $80(58 ; 96)$ & $83(70 ; 102)$ & $83(54 ; 95)$ & 0.649 \\
\hline \multicolumn{5}{|l|}{ Extension } \\
\hline Aorta ascendens & $28(17.4 \%)$ & $11(25.0 \%)$ & $3(9.7 \%)$ & 0.226 \\
\hline Aorta thoracalis descendens & $50(31.1 \%)$ & $8(18.2 \%)$ & $7(22.6 \%)$ & 0.191 \\
\hline Aorta abdominalis & $10(6.2 \%)$ & $4(9.1 \%)$ & $6(19.4 \%)$ & 0.055 \\
\hline Arteria iliaca & 75 (46.0\%) & $21(47.7 \%)$ & $15(48.8 \%)$ & 0.842 \\
\hline
\end{tabular}

Abbreviations: aPTT, activated partial thromboplastin time; INR, international normalized ratio; LVEF, left ventricular ejection fraction.

aSerum creatinine $>1.1 \mathrm{mg} / \mathrm{dL}$.

${ }^{\mathrm{b} C o n n e c t i v e ~ t i s s u e ~ d i s o r d e r s ~ s u m m a r i z e ~ M a r f a n ~ s y n d r o m e, ~ E h l e r s-D a n l o s ~ s y n d r o m e, ~ a n d ~ L o e y s-D i e t z ~ s y n d r o m e . ~}$

$p=0.019)$, whereas distal aortic arch entry tear group in comparison to isolated ascending aortic entry tear group showed similar results $(p=0.239)$. Moreover, incidence of gastrointestinal complications for distal aortic arch entry tear group in comparison to proximal aortic arch entry tear group showed a statistically significant nearly sevenfold higher odds ratio $(\mathrm{OR}=6.67, p=0.024)$, whereas odds ratios of to the two other entry tear groups were similar $(p=0.182$ and $p=0.077)$. Reopening for bleeding showed in terms of distal aortic arch entry tear group in comparison to isolated ascending aortic entry tear group a significantly higher odds ratio (OR $2.48, p=0.035$ ) as well as in-hospital mortality (OR 2.77, $p=0.022$ ) and month mortality (OR 3.33, $p=0.005)$. Month mortality showed also a significant difference for distal aortic arch entry tear group in comparison to proximal aortic entry tear group $(\mathrm{OR}=4.10, p=0.014)(-$ Table 4$)$. 
Table 2 Association of operative strategy for groups with aortic entry tear site in isolated ascending aorta, proximal aortic arch, and distal aortic arch

\begin{tabular}{|l|l|l|l|l|}
\hline & $\begin{array}{l}\text { Entry ascending } \\
\text { aorta }\end{array}$ & $\begin{array}{l}\text { Entry proximal } \\
\text { aortic arch }\end{array}$ & $\begin{array}{l}\text { Entry distal } \\
\text { aortic arch }\end{array}$ & $p$ Value \\
\hline Surgical strategy & & & & \\
\hline Isolated ascending aortic repair & $112(68.4 \%)$ & $10(22.2 \%)$ & $4(12.9 \%)$ & $<0.001$ \\
\hline Aortic hemiarch repair & $39(23.8 \%)$ & $23(51.1 \%)$ & $10(32.3 \%)$ & 0.002 \\
\hline Aortic arch repair & $13(7.9 \%)$ & $12(26.7 \%)$ & $17(54.8 \%)$ & $<0.001$ \\
\hline Bentall procedure & $55(33.5 \%)$ & $10(22.2 \%)$ & $7(22.6 \%)$ & 0.214 \\
\hline David procedure & $5(3.0 \%)$ & $2(4.4 \%)$ & $1(3.2 \%)$ & 0.898 \\
\hline CABG & $30(18.3 \%)$ & $4(8.9 \%)$ & $3(9.7 \%)$ & 0.193 \\
\hline Redo procedure & $11(6.7 \%)$ & $4(8.9 \%)$ & $3(9.7 \%)$ & 0.784 \\
\hline SBP & $118(72.4 \%)$ & $44(97.8 \%)$ & $28(90.3 \%)$ & $<0.001$ \\
\hline SBP bilateral & $80(49.1 \%)$ & $33(73.3 \%)$ & $22(78.6 \%)$ & $<0.001$ \\
\hline Cannulation & & & & \\
\hline Arteria axillaris & $137(83.5 \%)$ & $38(84.4 \%)$ & $19(61.3 \%)$ & 0.012 \\
\hline Aorta ascendens/ proximal arch & $23(14.0 \%)$ & $8(17.8 \%)$ & $10(33.3 \%)$ & 0.036 \\
\hline Arteria femoralis & $3(1.8 \%)$ & $1(2.2 \%)$ & $1(3.2 \%)$ & 0.881 \\
\hline Cardioplegia & & & & \\
\hline Buckberg & $144(87.8 \%)$ & $43(95.6 \%)$ & $26(86.7 \%)$ & 0.301 \\
\hline Calafiore & $16(9.8 \%)$ & $0(0.0 \%)$ & $4(13.3 \%)$ & 0.064 \\
\hline Bretschneider & $4(2.4 \%)$ & $2(4.4 \%)$ & $1(3.3 \%)$ & 0.771 \\
\hline
\end{tabular}

Abbreviations: CABG, coronary artery bypass grafting; SBP, selective brain perfusion.

\section{Short- and Long-Term Survival}

To analyze the impact of the three different entry tear groups on short- and long-term survival after surgery for Stanford A AAD, Kaplan-Meier survival estimation analysis and plot with up to 9-year follow-up were performed. Breslow (Generalized Wilcoxon) test was applied for calculation of significances for earlier (short-term) and Log-Rank (Mantel-Cox) test for later (long-term) follow-up phases. Our analysis showed statistically significant differences for short- and long-term survival for patients (Log-Rank $p=0.002$; Breslow $p=0.001$ ) and similar results for survival for patients free from major cerebrovascular events (Log-Rank $p=0.780$; Breslow $p=0.702$ ). A continuous variable with timeline for major cerebrovascular events syntonic to a variable (dichotomous variable: yes or no) with incidence of major cerebrovascular events was performed beginning with operation day up to 9-year follow-up which resulted at the end in two patient groups: one patient group with major cerebrovascular events and one group free from major cerebrovascular events.

The number of patients at risk of 9-year follow-up for entry tear in ascending aortic group versus proximal aortic arch group versus distal aortic arch group for overall cumulative survival were at 30 days $135: 37: 17$, at 6 months $124: 27: 11$, at 1 year (a) $113: 22: 9$, at 2 a $85: 14: 6$, at $3 a$ $70: 13: 3$, at $4 a$ 61:8:2, at $5 a$ $43: 7: 1$, at $6 a 35: 4: 0$, at $7 a$ 33:3:0, at 8a 9:1:0, at 9a 0:0:0 as well as for survival free from major cerebrovascular events at 30 days 116:24:8, at 6 months 105:20:6, at 1 year (a) 77:63:2 at 2a 77:17:4, at 3a
63:12:2, at 4 a $51: 7: 1$, at $5 a$ 37:6:0, at $6 a$ 29:4:0, at 7a $18: 3: 0$, at 8a 9:1:0 at 9a 0:0:0 (-Figs. 1 and 2; - Table 5).

Subgroup analysis of short- and long-term survival revealed significant differences in terms of male ( $\log -\operatorname{Rank} p=0.043$; Breslow $p=0.035$ ) and female gender (Log-Rank $p=0.004$; Breslow $p=0.001$ ), of patients under 65 years of age (LogRank $p=0.087$; Breslow $p=0.069)$, of patients above 65 years of age ( $\log -\operatorname{Rank} p=0.007$; Breslow $p=0.005)$, and of hypertensive patients (Log-Rank $p=0.003$; Breslow $p=0.002$ ) (-Table 5). All plots showed the poorest survival for distal aortic arch entry tear group in comparison to isolated ascending aorta or proximal aortic arch entry tear site group.

However, subgroup analysis for short- and long-term survival of patients free from major cerebrovascular events showed similar results for male and female gender, for patients under and above 65 years of age and hypertensive patients (Log-Rank and Breslow test $p>0.05$ ) (-Table 5). Distribution of causes of death (COD) after Stanford A AAD repair during 9-year follow-up showed highest incidence for bleeding, sepsis and multiorgan failure in terms of entry in distal aortic arch entry tear group (-Table 6).

\section{Discussion}

Stanford A AAD as a complex life-threatening disease is associated with high perioperative morbidity and mortality up to 10 to $25 \% .^{8-14}$ Therefore, early recognition and surgical correction are recommended to prevent devastating 
Table 3 Association of intra- and early postoperative variables with aortic entry tear site in isolated ascending aorta, proximal aortic, arch and distal aortic arch

\begin{tabular}{|c|c|c|c|c|}
\hline & $\begin{array}{l}\text { Entry ascending } \\
\text { aorta }\end{array}$ & $\begin{array}{l}\text { Entry proximal } \\
\text { aortic arch }\end{array}$ & $\begin{array}{l}\text { Entry distal } \\
\text { aortic arch }\end{array}$ & $p$ Value \\
\hline Cross clamp time (min) & $78(61 ; 115)$ & $99(77 ; 124)$ & $134(101 ; 172)$ & $<0.001$ \\
\hline Duration of surgery (min) & $313(245 ; 410)$ & $322(257 ; 398)$ & $402(286 ; 490)$ & 0.030 \\
\hline Cardiopulmonary bypass time (min) & $165(121 ; 211)$ & $193(155 ; 215)$ & $262(171 ; 262)$ & $<0.001$ \\
\hline SBP (min) & $20(12 ; 33)$ & $42(25 ; 62)$ & $55(38 ; 78)$ & $<0.001$ \\
\hline SBP flow (mL/min) & $900(900 ; 900)$ & $900(800 ; 900)$ & $900(900 ; 900)$ & 0.147 \\
\hline Reperfusion time (min) & $64(44 ; 83)$ & $71(60 ; 85)$ & $91(54 ; 145)$ & 0.024 \\
\hline RBC intraoperatively $(U)$ & $6(4 ; 9)$ & $7(5 ; 10)$ & $8(5 ; 9)$ & 0.436 \\
\hline FFP intraoperatively (U) & $6(4 ; 9)$ & $7(6 ; 8)$ & $6(4 ; 11)$ & 0.242 \\
\hline Platelets intraoperatively (U) & $2(1 ; 3)$ & $2(1 ; 2)$ & $2(1 ; 3)$ & 0.326 \\
\hline RBC postoperatively (U) & $5(2 ; 10)$ & $6(2 ; 11)$ & $7(1 ; 25)$ & 0.047 \\
\hline FFP postoperatively (U) & $3(0 ; 6)$ & $4(1 ; 9)$ & $5(0 ; 13)$ & 0.023 \\
\hline Platelets postoperatively (U) & $0(0 ; 1)$ & $1(0 ; 1)$ & $1(0 ; 2)$ & 0.326 \\
\hline ICU stay (days) & $5(2 ; 12)$ & $9(4 ; 13)$ & $14(3 ; 24)$ & 0.012 \\
\hline Time for intubation (days) & $2(1 ; 6)$ & $4(2 ; 10)$ & $4(1 ; 17)$ & 0.009 \\
\hline Drainage output over 24 hours (mL) & $959(578 ; 1,970)$ & $1485(985 ; 1,982)$ & $2,210(700 ; 3,000)$ & 0.027 \\
\hline Temporary neurological disorder & $53(33.5 \%)$ & $17(38.6 \%)$ & $11(40.7 \%)$ & 0.678 \\
\hline Major cerebrovascular events ${ }^{a}$ & $20(12.4 \%)$ & $12(27.3 \%)$ & $6(20.7 \%)$ & 0.048 \\
\hline Myocardial infarction & $47(28.8 \%)$ & $8(18.2 \%)$ & $10(34.5 \%)$ & 0.251 \\
\hline Gastrointestinal complications & $19(11.7 \%)$ & $2(4.5 \%)$ & $7(24.1 \%)$ & 0.040 \\
\hline Renal CVVH & $31(19.0 \%)$ & $7(15.9 \%)$ & $10(35.7 \%)$ & 0.092 \\
\hline Tracheostomy & $47(28.8 \%)$ & $13(29.5 \%)$ & $13(44.8 \%)$ & 0.224 \\
\hline Tachyarrhythmia absoluta & $59(36.4 \%)$ & $18(41.9 \%)$ & $11(37.9 \%)$ & 0.806 \\
\hline Infection & 74 (45.4\%) & $23(52.3 \%)$ & $16(55.2 \%)$ & 0.507 \\
\hline Reopening for bleeding & $32(19.8 \%)$ & $14(31.8 \%)$ & $16(37.9 \%)$ & 0.047 \\
\hline Bleeding & $73(45.1 \%)$ & 27 (60.0\%) & 17 (58.6\%) & 0.121 \\
\hline In-hospital stay (days) & $12(7 ; 19)$ & $13(10 ; 22)$ & $15(2 ; 26)$ & 0.389 \\
\hline Intraoperative mortality & $4(2.5 \%)$ & $1(2.2 \%)$ & $6(19.4 \%)$ & $<0.001$ \\
\hline ICU mortality & $22(13.5 \%)$ & $6(13.3 \%)$ & $5(16.7 \%)$ & 0.893 \\
\hline In-hospital mortality & 25 (15.9\%) & $8(18.2 \%)$ & 10 (34.5\%) & 0.062 \\
\hline 30-day mortality & $26(16.0 \%)$ & $6(13.3 \%)$ & $12(38.7 \%)$ & 0.007 \\
\hline
\end{tabular}

Abbreviations: CVVH, continuous veno-venous hemofiltration; FFP, fresh frozen plasma; ICU, intensive care unit; RBC, red blood cell; SBP, selective brain perfusion time; $\mathrm{U}$, units.

aschemic and hemorrhagic stroke.

complications, such as aortic rupture. To this day, less attention has been paid to the impact of different aortic entry tear sites on early outcomes, short- and long-term survival of patients suffering from Stanford A AAD.

In literature, there were only few studies evaluating the impact of different entry tear sites on outcomes of patients with Stanford A AAD. ${ }^{4,5}$ Further, in contrast to previous reports on $A A D$, our group used multinominal logistic regression for subgroup analysis. The aim of this study was to compare the impact of three different aortic entry tear sites on early outcomes, short- and long-term survival of patients suffering from Stanford A AAD at a high-volume center.
In terms of analysis of baseline characteristics, most parameters showed similar results, so our patients cohort featured well-balanced. Takami et al corroborated our results with focus on age, gender, incidence of hypertension, coronary artery disease, and incidence of diabetes. ${ }^{6}$ They also did not find any correlation between sites of primary entry tear and patients' neurological status. Nevertheless, one should keep in mind that entry tear classification by Takami et al differed from our classification. We analyzed location of isolated ascending aortic entry tear versus proximal aortic arch entry tear versus distal aortic arch entry tear, whereas Takami et al categorized dissection entry tears as to be 
Table 4 Multinominal logistic regression analysis of selected variables of patients with Stanford A AAD. Odds ratios (OR), $95 \%$ confidence intervals $(95 \% \mathrm{Cl})$ and $p$ values of patient groups with different aortic entry tear sites

\begin{tabular}{|l|l|l|l|}
\hline & OR & $95 \% \mathrm{Cl}$ & $p$ Value \\
\hline Major cerebrovascular events $^{\mathrm{a}, \mathrm{d}}$ & 2.65 & $1.17-5.95$ & 0.019 \\
\hline Major cerebrovascular events $^{\mathrm{b}, \mathrm{d}}$ & 1.84 & $0.67-5.08$ & 0.239 \\
\hline Gastrointestinal complications $^{\mathrm{a}}$ & 0.36 & $0.08-1.61$ & 0.182 \\
\hline Gastrointestinal complications $^{\mathrm{b}}$ & 2.41 & $0.91-6.41$ & 0.077 \\
\hline Gastrointestinal complications $^{\mathrm{c}}$ & 6.67 & $1.27-34.48$ & 0.024 \\
\hline Bleeding $^{\mathrm{a}}$ & 1.83 & $0.93-3.58$ & 0.078 \\
\hline Bleeding $^{\mathrm{b}}$ & 1.73 & $0.78-3.85$ & 0.181 \\
\hline Reopening for bleeding $^{\mathrm{a}}$ & 1.90 & $0.90-3.98$ & 0.092 \\
\hline Reopening for bleeding $^{\mathrm{b}}$ & 2.48 & $1.07-5.78$ & 0.035 \\
\hline In-hospital mortality $^{\mathrm{a}}$ & 1.17 & $0.49-2.82$ & 0.721 \\
\hline In-hospital mortality $^{\mathrm{b}}$ & 2.77 & $1.16-6.66$ & 0.022 \\
\hline Month mortality $^{\mathrm{a}}$ & 0.81 & $0.31-2.11$ & 0.667 \\
\hline Month mortality $^{\mathrm{b}}$ & 3.33 & $1.44-7.69$ & 0.005 \\
\hline Month mortality $^{\mathrm{c}}$ & 4.10 & $1.33-12.65$ & 0.014 \\
\hline
\end{tabular}

Abbreviation: AAD, acute aortic dissection.

aproximal aortic entry tear group in comparison to isolated ascending aortic entry tear group.

${ }^{b}$ Distal aortic entry tear group in comparison to isolated ascending aortic entry tear group.

'Distal aortic entry tear group in comparison to proximal aortic entry tear group.

${ }^{d}$ ischemic and hemorrhagic stroke.

located in proximal ascending, middle ascending, and distal ascending aortic arch. ${ }^{6}$ This fact might bias comparison of the studies.

Further, in our study we showed that the more distal the location of the primary entry tear in the aorta was, the more invasive surgery had to be performed corresponding to higher mortality rates. Takami et al stated that mortality rates were significantly higher in patients with primary entry tear sites in middle ascending and in distal ascending aortic arch than in proximal ascending aortic arch. ${ }^{6}$ Our results support these findings corresponding to our classification: mortality of distal aortic arch entry tear group was significant higher in comparison to isolated ascending or proximal aortic arch entry tear site group. Arch replacement received $54.8 \%$ of all patients with distal aortic arch entry tear. Further $32.3 \%$ of patients received hemiarch replacement with being aortic arch entry tear on the border toward hemiarch region. Smaller surgical approach was chosen to minimize perioperative complications. In terms of patients receiving ascending aortic repair entry tears were located in ascending aorta and in distal aortic arch. This may explain high mortality (32.8\%) in distal aortic arch entry tear group.

Ma et al found out that $12.5 \%$ of all cases in terms of the three different entry tear sites of Stanford A AAD were located in distal aortic arch. ${ }^{5}$ Corroborating these results, we showed in our study that the incidence of an entry tear site in distal aortic arch was $12.9 \%$. Moreover, Ma et al stated that patients with aortic arch entry tear were older in comparison to the other two patient groups. ${ }^{5}$ In contrast to these results, we did not find any significant differences $(p=0.093)$. In our trial, most entry tear sites were found to be located in isolated ascending aorta (68.3\%) and also Urbanski et al stated that Stanford A dissections most frequently originated from intimal tears in the ascending aorta. ${ }^{4}$ Other studies revealed that the intimal dissection tear was often found in segments exposed to the greatest shear stress which is most frequently in ascending aorta $^{15}$ and thus, hypertension can directly act as a parietal stressor and indirectly as a proinflammatory trigger, mainly inducing macrophage recruitment and activation but our study revealed that hypertension was similarly distributed among the three entry tear site groups. ${ }^{16}$

Omura et al stated that incidence of visceral or renal malperfusion at the time of diagnosis in patients with proximal or distal aortic arch entry tear was a common phenomenon and should alert physicians to think about looking for entry sites beyond the ascending aorta and adapt surgical strategy accordingly. ${ }^{17}$ However, in this study no

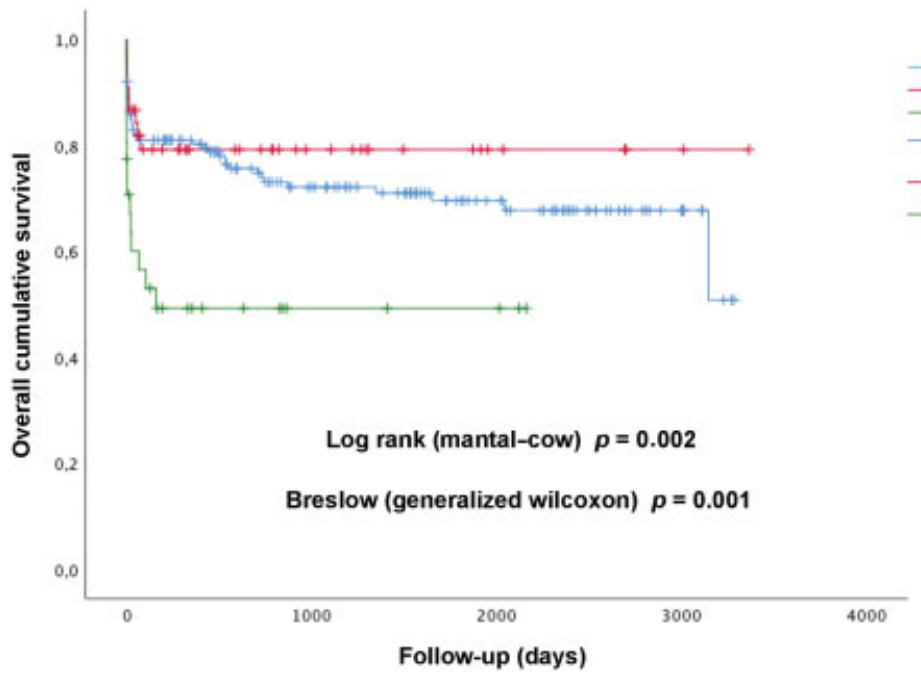

Fig. 1 Kaplan-Meier survival estimation plot for overall cumulative survival of patient groups with different aortic entry tear sites. 


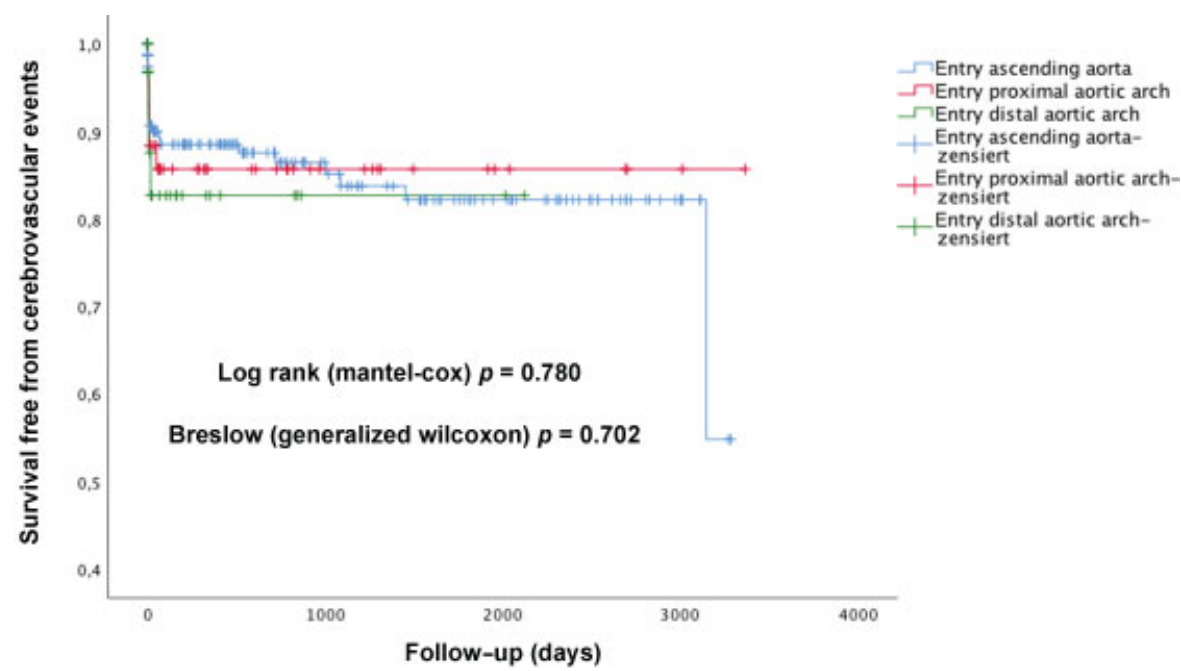

Fig. 2 Kaplan-Meier survival estimation plot for survival of patient groups free from cerebrovascular events with different aortic entry tear sites.

statistically significant differences were found $(p=0.277)$ in terms of malperfusion among incidence of aortic entry tear site in ascending aorta versus proximal or distal aortic arch (-Table 1).

Short- and long-term survival of patients revealed significant differences among the three aortic entry tear groups as well as between subgroups of men, women, patients under and above 65 years of age, and hypertensive patients. All Kaplan-Meier survival estimation plots showed poorest survival of patients in distal aortic arch entry tear site group. Surprisingly, our literature research did not reveal data dealing with the addressed patient groups and short- and long-term issues. Interestingly, in contrast to Stanford A AAD, literature provides a lot of data for Stanford B dissections and the impact of different entry tear sites. ${ }^{18,19}$

Due to still controversial results on early outcomes and shortand long-term survival of patients and different classifications in literature for entry tear sites in patients undergoing aortic repair for Stanford A AAD, further investigations are needed. Nevertheless, surgical approach should always be adapted to patients' individual circumstances. ${ }^{20}$ Each case should be evaluated accurately to achieve acceptable outcomes. ${ }^{21}$ Newer techniques as tear-oriented endovascular repair would be an alternative therapeutic option supplanting surgery. ${ }^{4}$

\section{Limitations of the Study}

This study is a retrospective analysis of collected registry data from a single center. The study power was limited due a relatively small patient cohort. The nonrandomized design as well as complexity and variability of the pathophysiology and morphology of Stanford A AAD may also have affected the results. This study represents the experience of a single large tertiary referral center and might not be generalized to other centers.

\section{Conclusion}

The present analysis showed that the specificity of the aortic entry tear site significantly influences early outcomes, short-

Table 5 Kaplan-Meier survival estimation analysis. $p$ Values of Log-Rank (Mantel-Cox) test and Breslow (Generalized Wilcoxon) test for survival and survival free from major cerebrovascular events of various patient cohorts. Comparison of aortic entry tear in isolated ascending aorta versus proximal aortic arch versus distal aortic arch of patient groups with Stanford A AAD

\begin{tabular}{|c|c|c|c|c|}
\hline & \multicolumn{2}{|l|}{ Survivala $^{\mathrm{a}}$} & \multicolumn{2}{|c|}{$\begin{array}{l}\text { Survival free from major } \\
\text { cerebrovascular events }\end{array}$} \\
\hline & $\begin{array}{l}\text { Log-rank } \\
p \text { value }\end{array}$ & $\begin{array}{l}\text { Breslow } \\
p \text { value }\end{array}$ & $\begin{array}{l}\text { Log-rank } \\
p \text { value }\end{array}$ & $\begin{array}{l}\text { Breslow } \\
p \text { value }\end{array}$ \\
\hline Patients of either gender & 0.002 & 0.001 & 0.780 & 0.702 \\
\hline Men & 0.043 & 0.035 & 0.567 & 0.455 \\
\hline Women & 0.004 & 0.001 & 0.147 & 0.141 \\
\hline Patients $<65$ years of age & 0.087 & 0.069 & 0.215 & 0.186 \\
\hline Patients $\geq 65$ years of age & 0.007 & 0.005 & 0.481 & 0.534 \\
\hline Hypertensive patients & 0.003 & 0.002 & 0.998 & 0.946 \\
\hline
\end{tabular}

Abbreviation: AAD, acute aortic dissection.

a Distal aortic arch entry tear group showed significantly poorest survival. 
Table 6 Causes of death (COD) after Stanford A AAD repair during 9-year follow-up in percent (\%) of aortic entry tear site group

\begin{tabular}{|l|l|l|l|l|}
\hline \multirow{2}{*}{$\begin{array}{l}\text { Myocardial } \\
\text { infarction }\end{array}$} & $\begin{array}{l}\text { Entry } \\
\text { ascending } \\
\text { aorta }\end{array}$ & $\begin{array}{l}\text { Entry } \\
\text { proximal } \\
\text { aortic } \\
\text { arch }\end{array}$ & $\begin{array}{l}\text { Entry } \\
\text { distal } \\
\text { aortic } \\
\text { arch }\end{array}$ \\
\cline { 2 - 5 } & $\mathrm{b}$ & 0.7 & 6.7 & 6.7 \\
\hline $\begin{array}{l}\text { Major } \\
\text { cerebrovascular } \\
\text { events }\end{array}$ & $\mathrm{a}$ & 3.7 & 2.6 & 0 \\
\hline & $\mathrm{b}$ & 0 & 4.4 & 3.3 \\
\hline \multirow{3}{*}{$\begin{array}{l}\text { Bleeding } \\
\text { Sepsis }\end{array}$} & $\mathrm{a}$ & 2.5 & 0 & 0 \\
\cline { 2 - 5 } & $\mathrm{b}$ & 0 & 4.4 & 13.3 \\
\hline & $\mathrm{a}$ & 4.9 & 0 & 0 \\
\hline & $\mathrm{b}$ & 2.6 & 2.2 & 10.0 \\
\hline MOF & $\mathrm{a}$ & 3.1 & 0.5 & 1.0 \\
\cline { 2 - 5 } & $\mathrm{b}$ & 1.5 & 2.2 & 23.3 \\
\hline Other & $\mathrm{a}$ & 6.7 & 0 & 11.1 \\
\cline { 2 - 5 } & $\mathrm{b}$ & 8.0 & 0 & 0 \\
\hline
\end{tabular}

Abbreviation: AAD, acute aortic dissection.

Note: (a) COD from operation day onward up to 9-year follow-up. (b) COD from 30 days after surgery onward up to 9-year follow-up. ${ }^{\mathrm{a}} \mathrm{MOF}$ multiorgan failure.

and long-term survival of patients with Stanford A AAD, whereas survival of patients free from major cerebrovascular events was similar among the three entry tear groups. Distal aortic entry tear site group showed poorest outcomes and survival.

\section{Funding}

This research received no specific grant from any funding agency in the public, commercial, or not-for-profit sectors.

\section{Conflict of Interest}

The authors declare that there is no conflict of interest.

\section{References}

1 Czerny M. Re: Impact of the entry site on late outcome in acute Stanford type B aortic dissection. Eur J Cardiothorac Surg 2015;48 (05):662-663

2 Levy D, Le J. Aortic, Dissection, in StatPearls. Treasure Island (FL) 2017

3 Lansman SL, Saunders PC, Malekan R, Spielvogel D. Acute aortic syndrome. J Thorac Cardiovasc Surg 2010;140(6, Suppl):S92-S97, discussion S142-S146

4 Urbanski PP, Sodah A, Matveeva A, et al. Importance of accurately locating the entry site for endovascular treatment of retrograde
Type A acute aortic dissection. Interact Cardiovasc Thorac Surg 2018;26(05):731-737

5 Ma WG, Zhang W, Wang LF, et al. Type A aortic dissection with arch entry tear: surgical experience in 104 patients over a 12-year period. J Thorac Cardiovasc Surg 2016;151(06):1581-1592

6 Takami Y, Tajima K, Kato W, et al. Can we predict the site of entry tear by computed tomography in patients with acute type A aortic dissection? Clin Cardiol 2012;35(08):500-504

7 Lee TC, Kon Z, Cheema FH, et al. Contemporary management and outcomes of acute type A aortic dissection: an analysis of the STS adult cardiac surgery database. J Card Surg 2018;33(01):7-18

8 Sabashnikov A, Heinen S, Deppe AC, et al. Impact of gender on long-term outcomes after surgical repair for acute Stanford A aortic dissection: a propensity score matched analysis. Interact Cardiovasc Thorac Surg 2017;24(05):702-707

9 Sabashnikov A, Heinen S, Deppe AC, et al. Axillar or aortic cannulation for aortic repair in patients with Stanford A dissection? Ann Thorac Surg 2016;102(03):787-794

10 Cabasa A, Pochettino A. Surgical management and outcomes of type A dissection-the Mayo Clinic experience. Ann Cardiothorac Surg 2016;5(04):296-309

11 Nishida H, Tabata M, Fukui T, Takanashi S. Surgical strategy and outcome for aortic root in patients undergoing repair of acute type $A$ aortic dissection. Ann Thorac Surg 2016;101(04):1464-1469

12 Bavaria JE, Brinster DR, Gorman RC, Woo YJ, Gleason T, Pochettino A. Advances in the treatment of acute type A dissection: an integrated approach. Ann Thorac Surg 2002;74(05):S1848-S1852, discussion S1857-S1863

13 Song $\mathrm{MH}$. A learning curve in aortic dissection surgery with the use of cumulative sum analysis. Nagoya J Med Sci 2014;76(1-2):51-57

14 Trimarchi S, Nienaber CA, Rampoldi V, et al; International Registry of Acute Aortic Dissection Investigators. Contemporary results of surgery in acute type A aortic dissection: The International Registry of Acute Aortic Dissection experience. J Thorac Cardiovasc Surg 2005;129(01):112-122

15 Gawinecka J, Schönrath F, von Eckardstein A. Acute aortic dissection: pathogenesis, risk factors and diagnosis. Swiss Med Wkly 2017;147:w14489

16 Hahn AW, Jonas U, Bühler FR, Resink TJ. Activation of human peripheral monocytes by angiotensin II. FEBS Lett 1994;347(23):178-180

17 Omura A, Nakai $\mathrm{H}$, Minami $\mathrm{H}$, et al. [Early and long term outcomes of surgery for acute type A aortic dissection complicated with organ malperfusion]. Kyobu Geka 2016;69(04):304-309

18 Weiss G, Wolner I, Folkmann S, et al. The location of the primary entry tear in acute type B aortic dissection affects early outcome. Eur J Cardiothorac Surg 2012;42(03):571-576

19 Dziodzio T, Juraszek A, Reineke D, et al. Experimental acute type B aortic dissection: different sites of primary entry tears cause different ways of propagation. Ann Thorac Surg 2011;91(03):724-727

20 Kazui T, Washiyama N, Muhammad BA, et al. Extended total arch replacement for acute type a aortic dissection: experience with seventy patients. J Thorac Cardiovasc Surg 2000;119(03):558-565

21 Erbel R, Aboyans V, Boileau C, et al; ESC Committee for Practice Guidelines; The Task Force for the Diagnosis and Treatment of Aortic Diseases of the European Society of Cardiology (ESC). 2014 ESC Guidelines on the diagnosis and treatment of aortic diseases: document covering acute and chronic aortic diseases of the thoracic and abdominal aorta of the adult. Eur Heart J 2014;35 (41):2873-2926 